\title{
Further Explorations in Empowerment Theory: An Empirical Analysis of Psychological Empowerment ${ }^{1}$
}

\author{
Marc A. Zimmerman, ${ }^{2}$ Barbara A. Israel, Amy Schulz, \\ and Barry Checkoway
}

University of Michigan

Developed empowerment theory and replicated previous research on citizen participation and perceived control. Few investigators have designed studies that specifically test empowerment theory. This research further extends a theoretical model of psychological empowerment that includes intrapersonal, interactional, and behavioral components, by studying a large randomly selected urban and suburban community sample and examining race differences. Results suggest that one underlying dimension that combines different measures of perceived control may be interpreted as the intrapersonal component of psychological empowerment, because it distinguishes groups defined by their level of participation in community organizations and activities (behavioral component). The association found between the intrapersonal and behavioral components is consistent with empowerment theory. Interaction effects between race groups and participation suggest that participation may be more strongly associated with the intrapersonal component of psychological empowerment for African Americans than for white individuals. Implications for empowerment theory and intervention design are discussed.

\footnotetext{
${ }^{1}$ The authors express appreciation to Steven Rosenstone who was the Principal Investigator for the Detroit Area Study from which the data for our study is based. We also thank Deborah A. Salem and the anonymous reviewers for their thoughtful comments on earlier drafts of this paper.

${ }^{2}$ All correspondence should be sent to Marc A. Zimmerman, Department of Health Behavior and Health Education, School of Public Health, University of Michigan, Ann Arbor, Michigan 48109-2029.
} 
Empowerment at the individual level of analysis is a process by which individuals gain mastery and control over their lives, and a critical understanding of their environment (Berger \& Neuhaus, 1977; Cornell Empowerment Group, 1989; Kieffer, 1984; Rappaport, 1984, 1987; Schulz \& Israel, 1990; Swift \& Levin, 1987; Zimmerman, 1990a). The form psychological empowerment (PE) takes depends on the context and population being studied (Rappaport, 1984; Zimmerman, in press). In the most general case, PE may be conceptualized to include intrapersonal, interactional, and behavioral components (Zimmerman, in press). The intrapersonal component refers to how people think about their capacity to influence social and political systems important to them. It is a self-perception that includes domain-specific perceived control (Paulhus, 1983), self-efficacy, motivation to exert control, and perceived competence. It may also include perceptions about the difficulty associated with trying to exert control over community problems. This perceived difficulty may refer to beliefs about one's own capacity to influence social and political systems, or to beliefs about people in general (Zimmerman \& Rappaport, 1988).

The interactional component refers to the transactions between persons and environments that enable one to successfully master social or political systems. It includes knowledge about the resources needed to achieve goals (i.e., resource mobilization, see McCarthy \& Zald, 1977), understanding causal agents (Sue \& Zane, 1980), a critical awareness of one's environment (Freire, 1973; Kieffer, 1984), and the development of decision-making and problem-solving skills necessary to actively engage one's environment. The interactional component has not been studied directly, but it may be essential to the construct of PE because it connects self-perceptions about control (intrapersonal component) with what one does to exert influence (behavioral component).

The behavioral component of PE refers to the specific actions one takes to exercise influence on the social and political environment through participation in community organizations and activities. It includes participation in community organizations such as neighborhood associations, political groups, self-help groups, church or religious groups, and service organizations. Other aspects of the behavioral component include participation in community-related activities such as helping others cope with problems in living, contacting public officials, or organizing a neighborhood around an issue. Several investigators have suggested that participation in voluntary organizations is associated with psychological empowerment (Berger \& Neuhaus, 1977; Prestby, Wandersman, Florin, Rich, \& Chavis, 1990; Zimmerman \& 
Rappaport, 1988). The specific operationalization of psychological empowerment for a particular study, however, depends on the population and context being studied.

To date, few empirical investigations have been undertaken to test explicitly psychological empowerment theory. Empowerment theory is widely written about (Gershick, Israel, \& Checkoway, 1990; Rappaport, 1981, 1985; Swift \& Levin, 1987; Zimmerman, in press), but a lack of specification and empirically tested theory has limited our understanding of the construct. Further refinement of empowerment theory is needed to more clearly understand the natural settings in which individuals may gain a sense of empowerment, describe how and why interventions designed to empower individuals are effective or ineffective, study the mechanisms involved in the empowerment process, and identify contextual characteristics that may inhibit or promote the development of PE.

Two studies that are particularly related to PE theory employed different methodologies and found similar results. Kieffer (1984) conducted in-depth interviews with 15 individuals who emerged as leaders in grass-roots organizations. He concluded that empowerment at the individual level of analysis includes the development of skills necessary to participate effectively in community decision making, and comprises elements of self-esteem, a sense of causal importance, and perceived efficacy. In a quantitative analysis of the association between participation and perceived control Zimmerman and Rappaport (1988) found similar results. They found the combined variance of the 11 measures of perceived control formed one underlying dimension that distinguished high-participation groups from low- or no-participation groups. Similar results were found for samples of students and community residents across three different measures of participation. The results of these two studies support the idea that psychological empowerment includes personal control, a sense of competence, a critical awareness of the sociopolitical environment, and participation in community organizations and activities.

The theory of psychological empowerment posited here and reported in previous research suggests that the combined variance of multiple measures of perceived control (e.g., personal control, perceived efficacy) should form a single underlying dimension that may be identified as the intrapersonal component of psychological empowerment (Zimmerman \& Rappaport, 1988). For this underlying dimension to be consistent with PE theory in the context of voluntary organization membership, it should also be associated with measures representing the 
behavioral component of PE (e.g., participation in community organizations and activities).

For those individuals who participate in such community organizations and activities, the intrapersonal component of psychological empowerment may be hypothesized to include measures of perceived control consisting of personal and community control, perceived efficacy for influencing community decisions, and beliefs about the difficulty individuals perceive for influencing the sociopolitical system. The behavioral component might be expected to include participation, and holding leadership positions in community organizations, and activities. The interactional component may include some understanding of factors that hinder and enhance one's ability to influence community decisions, as well as, decision-making and problemsolving skills.

This study is an attempt to further examine this theoretical model by testing the hypothesized association between the intrapersonal and behavioral components of psychological empowerment among members of voluntary organizations. The study replicates previous research by examining how different measures of perceived control may combine to form a single construct that distinguishes individuals participating in community organizations at different levels. The study also extends previous research in three significant ways. First, it tests PE theory in a large randomly selected metropolitan population. Second, cluster analysis was used to develop meaningful behavior profiles that combined four measures of participation in community organizations.

Third, the study includes an analysis of race differences by comparing the association between the intrapersonal and behavioral components of psychological empowerment for white and African American individuals. An examination of race differences may be especially useful because most of the prior empirical work on empowerment has been based on predominantly white samples. Rappaport (1984) suggested that empowerment processes and outcomes differ for different people in different contexts. In this study, differences by race are examined while controlling for age, education, and income in order to explore the independent effects of race.

This study examines three major questions: (a) whether three measures of perceived control combine to form a single theoretical dimension that can be interpreted as an intrapersonal component of psychological empowerment for voluntary organization members; (b) whether individuals involved in community organizations and activities score higher on the intrapersonal component of PE than their less actively involved counterparts; and (c) whether differences are observed for PE among white and African American individuals. 


\section{METHOD}

\section{Sampling and Data Collection Procedure}

A multistage area probability sample of housing units in a tricounty area that included Detroit, Michigan was used to select the sample. ${ }^{3}$ The primary sampling unit was defined as geographically and physically bounded parcels of land (segments) based on 1980 Census tract data. Each segment was required to have at least 96 occupied housing units. These segments were then grouped into three general strata defined by geographical location, proportion of family households, and age of the neighborhood. The sample was randomly selected by housing units within each of the strata within each land segment. A supplemental sample from Detroit was also drawn to insure a sufficient number of respondents from the central city.

Households were sent a letter describing the study, informing residents that their household had been randomly selected, and notifying them that an interviewer would come to the house to schedule an in-person interview. Only individuals 18 years or older were eligible. The specific person selected to be interviewed in multiple person households was determined by a random selection procedure described by Kish (1965). In this procedure each member of the household over 18 was assigned a number and randomly selected. Interviews were conducted in the respondents' home and lasted from 34-175 minutes $(M=70, S D=17.5)$.

The response rate for the total sample was $64.9 \%$, the supplemental sample response rate was $60.7 \%$, and the response rate for the tricounty area without the supplemental sample was $69.6 \%$. The final sample size was 916 , but was reduced in most analyses due to missing data. The sample size for each analysis in this study is reported and comparisons between individuals included in analyses and those excluded are reported.

\section{Sample}

The average age of respondents was 44 years $(S D=17.7, n=911$ and ranged from 18-94. One third of the respondents reported they had completed high school, $26 \%$ reported they had not received a high school diploma, and $13 \%$ reported a bachelor's degree or higher. The sample included 432 (47\%) African Americans and 444 (48\%) whites (the remaining

\footnotetext{
${ }^{3}$ This study was a part of a larger study conducted in 1989 - the Detroit Area Study - that examined residents' attitudes about school, crime, and local policy issues, and participation in voluntary organizations.
} 
5\% included Asians, Native Americans, and other race groups). The sample included $556(61 \%)$ female respondents. The average income for respondents $(n=800)$ was between $\$ 17,000$ and $\$ 20,000$ and ranged from below $\$ 3,000$ to over $\$ 90,000$.

\section{Independent Variables}

Four measures of participation were used in a cluster analysis to identify groups defined by different levels of participation.

Number of Organizations. The total number of organizations of which respondents reported being a member was one of the participation measures. The average number of organizations in which respondents participated was $1.7(S D=1.9, n=916)$ and ranged from 0 to 10 . Most individuals were members of one or two organizations $(44 \%, n=392)$ and $32 \%(n=296)$ were not involved in any organization.

Leadership. Leadership in the organization that respondents identified as their most important organizational affiliation was a second participation measure. Nonparticipants were given a score of 0 , participants who held no leadership positions were given a score of 1 , and organizational leaders were given a score of 2 . Individuals who reported being an officer, serving on a committee, or helping organize meetings during the last 12 months received a score of 2 on this variable. Over a third (35\%) of the individuals involved in an organization reported holding some kind of leadership position in their most important organization $(n=218)$.

Amount of Organizational Activity. A 3-point Likert item $(3=$ very active; 2 = somewhat active; $1=$ not very active) indicating the amount of active involvement over the last 12 months in the respondents' most important organization was a third measure of participation (the 292 nonparticipants were given a score of 0 ). The mean activity score was 1.4 $(S D=1.2)$. Of the respondents who reported some organizational participation, $35 \%$ reported they were very active in their most important organization $(n=217)$ and $31 \%$ reported they were not very active $(n=189)$.

Community Activities. The final measure of participation was the total number of community activities in which respondents participated. Using a 10 -item checklist, respondents were asked if they ever participate in activities such as attending a public meeting, writing to a public official, discussing politics with family members, contributing money, and taking some action to do something about a community issue. Respondents were not given an opportunity to include activities that did not appear in the checklist. Scores for this measure could range from 10-50 $(1=$ did not do the 
activity; $5=$ did the activity). The mean for this measure was 18.0 $(S D=9.2, n=908)$. Thirty-eight percent of the sample reported participating in no community activities $(n=341)$.

\section{Dependent Variables}

Three measures of perceived control were used in the analysis.

Personal and Community Control. A 7-item measure of the respondents' sense of control in personal and community decisions was used. The measure used a 4-point Likert scale ( $4=$ strongly agree), had a mean of $2.8(S D=.47, n=843)$, and a Cronbach alpha of .68. Examples of items in this scale include: (a) "I have control over decisions that affect my life."; (b) "I am satisfied with the amount of control I have over decisions that affect my life."; (c) "I can influence decisions that affect my community."; (d) "By working together, people in my community can influence decisions that affect the community."

Perceived Effectiveness. An 8-item measure of the respondents' perceived effectiveness of different actions to influence community decisions (e.g., protest demonstration, writing letters, attending meetings, boycotting) was used. This measure also used a 4 -point Likert scale $(4=$ very effective), had a mean of $2.9(S D=.56, n=848)$, and a Cronbach alpha of 79. A sample item is: "How effective would it be to attend meetings about some community issue or problem in convincing public officials and institutions to do something?" The correlation of perceived effectiveness with personal and community control is $.17(p<.01)$.

Perceived Difficulty. A 3-item, 4-point Likert scale was used to measure perceived difficulty for influencing community, school, and crime problems. A sample item asks: "Community problems are often so complicated that even informed people can't figure out what should be done about them." The other items are similar except they ask for opinions regarding the local public schools and the problem of crime. High scores on this variable indicated that respondents believed it was less difficult for "even informed people" to solve the problem. The mean for this measure was $2.2(S D=.80, n=899)$ and the Cronbach alpha was .78 . The correlation of perceived difficulty with personal and community control is .03 (ns) and .02 (ns) with perceived effectiveness.

\section{Data Analytic Procedure}

A three-step data analytic process for examining the association between the intrapersonal and behavioral components of psychological 
empowerment theory was used. The first data analytic step was to assign individuals to participation groups using multivariate behavioral profiles. A cluster analytic approach was used to develop participation profiles based upon respondents' level of participation in community organizations and community activities. A cluster solution was computed for two randomly selected halves of the sample to determine if a stable cluster solution could be found. A total sample cluster solution was then computed and used for group assignment in subsequent analyses.

Ward's method was the clustering technique used because the algorithm provides maximum between-group variance and minimum within-group variance (Averred, 1974). Two procedures recommended by Aldenderfer and Blashfield (1984) were used to determine the number of clusters to retain. These were (a) graphing the number of clusters by the proximity coefficients and inspecting the jump in values of the proximity coefficients; and (b) examining the theoretical meaningfulness of different solutions (see also Averred, 1974). Respondents' gender, race, age, education, and income were then compared across the clusters (i.e., participation groups) to identify variables that may confound analyses of the association between the intrapersonal and behavioral components of psychological empowerment.

The second analytic step was a multiple analysis of variance (MANOVA) to compare groups defined by their level of participation. The dependent variables were the three measures of perceived control. Demographic variables found to differ across groups were included as covariates in the MANOVA model in order to control for potential confounds in analyses examining the association between the intrapersonal and behavioral components of psychological empowerment. Race group and gender were introduced as additional factors if they were not equally distributed across participation groups.

Finally, a discriminant function analysis was conducted to help interpret the underlying dimension(s) formed by the dependent variables that distinguished groups (Bray \& Maxwell, 1982). This statistical technique computes a linear composite of the dependent variables based upon the discriminant function loadings of the individual variables (Tatsuoka, 1971). The linear composite is a theoretical construct that can then be interpreted much like a factor in a factor analytic solution. It is important to point out that the discriminant function algorithm forms one less function than the number of groups included in the analysis (e.g., three groups form up to two discriminant functions) and then tests each for statistical significance (Tatsuoka, 1971). 
Table I. Correlations Among the Four Participation Measures ${ }^{a}$

\begin{tabular}{llllll}
\hline & & 1 & 2 & 3 & 4 \\
\hline 1 & No. of organizations & - & & & \\
2 & Organizational leadership & .57 & - & & \\
3 & Organizational activity & .58 & .86 & - & \\
4 & Community activities & .51 & .38 & .37 & - \\
\hline
\end{tabular}

${ }^{a}$ All correlations are significant at the .01 level.

\section{RESULTS}

\section{Cluster Analysis}

The correlation matrix for the participation indices are reported in Table I. All correlations are significant at the .01 level. A three-cluster solution was selected for the development of participation profiles because the jump in proximity measures between the second and third clusters was twice that of any previous cluster comparison in both the subsample and final sample analyses. The three-group solution is also consistent with previous research (Zimmerman \& Rappaport, 1988). Means for the cluster variables and group size for each of the clusters in the total sample solution ( $n=896,98 \%$ of the sample) are reported in Table II. The groups are roughly equal in size. The first group includes those individuals not involved in any organization and whose participation in community activities is at the lowest level. The second group includes individuals who participate in organizations at a low level and whose community activism is at a low level similar to the noninvolved group. The third group comprises individuals with the highest level of participation in both organizations and community activities.

The solutions for each of the $50 \%$ subsamples were very similar. Over all three groups, individuals were $90 \%$ correctly classified from the subsample solution and the total sample solution. The nonparticipant group was $100 \%$ correctly classified in the two analyses. The most discrepancies were found between the two participant groups. In all of the discrepant cases $(n=90)$, individuals were placed in the group with a low level of participation in the $50 \%$ sample analysis, but were assigned to the high level of participation group in the total sample analysis. 
Table II. Descriptive Statistics for the Full Sample Cluster Solution

\begin{tabular}{|c|c|c|c|}
\hline \multirow[b]{2}{*}{ Variable } & \multicolumn{3}{|c|}{ Cluster $^{a}$} \\
\hline & $\begin{array}{c}1 \\
(n=291)\end{array}$ & $\begin{array}{c}2 \\
(n=328)\end{array}$ & $\begin{array}{c}3 \\
(n=277)\end{array}$ \\
\hline \multicolumn{4}{|c|}{ No. of organizations } \\
\hline$M$ & 0 & 1.5 & 3.6 \\
\hline$S D$ & 0 & 0.67 & 2.2 \\
\hline \multicolumn{4}{|c|}{ Organizational leadership } \\
\hline$M$ & 0 & 1.4 & 1.4 \\
\hline$S D$ & 0 & 0.48 & 0.48 \\
\hline \multicolumn{4}{|c|}{ Organizational activity } \\
\hline$M$ & 0 & 2.0 & 2.1 \\
\hline$S D$ & 0 & 0.85 & 0.76 \\
\hline \multicolumn{4}{|c|}{ Community activities } \\
\hline$M$ & 13.3 & 14.1 & 27.3 \\
\hline$S D$ & 5.1 & 4.8 & 9.4 \\
\hline
\end{tabular}

\section{Demographics}

Males and females were equally distributed across the three groups, $\chi^{2}(2)=5.0$, ns. The chi-square analysis for race group, however, was just beyond the significance level of $.05, \chi^{2}(2)=5.9, p=.052$. African Americans were less likely to be in the most highly involved group. Individuals in the participation groups (Clusters 2 and 3 ) were older, $F(2$, $888)=8.44, p<.01$, had more years of education, $F(2,888)=66.65$, $p<.01$, and higher incomes, $F(2,780)=33.88, p<.01$, than individuals in the noninvolved group. Duncan multiple comparisons also indicated that the high-participation group had more education and income than the lowparticipation group.

\section{Multiple Analysis of Variance}

A multiple analysis of variance tested for group differences for the three perceived control measures. Respondents' race was also 
included in this analysis because of the strong trend found in the chisquare analysis for race and participation groups. Thus, a $3 \times 2$ factorial design (participation group $\times$ race) was used in the multiple analysis of variance test. Age, education, and income were entered as covariates in the model because of the differences found across participation groups on these variables. Analysis of sex differences was not included because men and women were equally distributed across participation groups.

The sample for the MANCOVA analysis was reduced to $646(71 \%$ of the total sample) due to missing data. Respondents omitted from analyses were equally distributed across participation groups, $\chi^{2}(2)=0.52$, ns. Comparisons between individuals with complete data with respondents who were omitted from the final MANCOVA due to missing data on at least one measure found only one difference. Individuals with complete data were younger than those excluded in the final analysis, $t(452)=3.49, p<.01$, but no differences were found for education, $t(421)=-1.26$, ns, or income, $t(235)=0.51$, ns. No differences were found for race group, $\chi^{2}(1)=0.65$, ns, and gender, $\chi^{2}(1)=0.97$, ns, distributions across participation groups or across groups defined by whether or not respondents had complete data. The smallest sample for the missing data group was 152 for the income analysis and other analyses had 200 or more. Forty-six individuals $(5 \%)$ were also omitted from the MANCOVA because they were neither white nor African American.

Interaction effects for race and participation were found in the multivariate analysis, $F(6,1272)=6.00, p<.05$. Univariate analysis of variance results for the interaction effects indicate that personal and community control was highest in the high-participation group for both African Americans and whites, but African Americans had lower scores than whites in the low-participation group and exceeded the whites in the middle- and high-participation groups, $F(2,637)=3.65, p<.05$. Perceived difficulty showed a trend that indicated less perceived difficulty in the high-participation groups, but whites in the high-participation group reported the lowest level of perceived difficulty, $F(2,637)=2.57, p=.08$. Perceived effectiveness did not differ across groups, $F(2,637)=0.52$, ns. Table III presents the means and standard deviations for groups crossed by race and participation.

Participation group main effects were found in the multivariate analysis, $F(6,1272)=5.94, p<.01$. Univariate analysis of variance results for the participation group main effect indicate that personal and community control, $F(2,637)=6.92, p<.01$, perceived effectiveness, $F(2$, $637)=8.22, p<.01$, and perceived difficulty, $F(2,637)=4.67, p<.01$, 
Table III. Means, Standard Deviations, and Group Size for Perceived Control Measures Across Participation and Race Groups

\begin{tabular}{|c|c|c|c|}
\hline & \multicolumn{3}{|c|}{ Participation group ${ }^{a}$} \\
\hline & 1 & 2 & 3 \\
\hline \multicolumn{4}{|c|}{ Personal and community control } \\
\hline \multicolumn{4}{|c|}{ African American } \\
\hline$M$ & 2.64 & 2.93 & 2.95 \\
\hline$S D$ & 0.51 & 0.47 & 0.42 \\
\hline$n$ & 114 & 114 & 89 \\
\hline \multicolumn{4}{|c|}{ White } \\
\hline$M$ & 2.82 & 2.86 & 2.93 \\
\hline$S D$ & 0.41 & 0.42 & 0.42 \\
\hline$n$ & 92 & 117 & 113 \\
\hline \multicolumn{4}{|c|}{ Perceived effectiveness } \\
\hline \multicolumn{4}{|c|}{ African American } \\
\hline$M$ & 2.88 & 2.95 & 3.13 \\
\hline$S D$ & 0.59 & 0.60 & 0.45 \\
\hline$n$ & 114 & 114 & 89 \\
\hline \multicolumn{4}{|c|}{ White } \\
\hline$M$ & 2.76 & 2.90 & 2.98 \\
\hline$S D$ & 0.60 & 0.46 & 0.43 \\
\hline$n$ & 92 & 117 & 113 \\
\hline \multicolumn{4}{|c|}{ Perceived difficulty } \\
\hline \multicolumn{4}{|c|}{ African American } \\
\hline$M$ & 2.05 & 2.14 & 2.19 \\
\hline$S D$ & 0.68 & 0.89 & 0.83 \\
\hline$n$ & 114 & 114 & 89 \\
\hline \multicolumn{4}{|l|}{ White } \\
\hline$M$ & 2.07 & 2.16 & 2.51 \\
\hline$S D$ & 0.68 & 0.73 & 0.80 \\
\hline$n$ & 92 & 117 & 113 \\
\hline
\end{tabular}

all differed across participation groups. In each case the nonparticipants scored the lowest on each variable and the high-participation group scored the highest. Multivariate main effects for race $F(6,635)=2.31$, ns, were not found. Table IV presents the means and standard deviations collapsed across African Americans and whites, and participation groups. 
Table IV. Means and Standard Deviations for Perceived Control Measures Collapsed Across Participation and Race Groups

\begin{tabular}{|c|c|c|c|}
\hline & \multicolumn{3}{|c|}{ Participation Group $^{a}$} \\
\hline & $\begin{array}{c}1 \\
n=206\end{array}$ & $\begin{array}{c}2 \\
n=237\end{array}$ & $\begin{array}{c}3 \\
n=203\end{array}$ \\
\hline \multicolumn{4}{|c|}{ Personal and community control } \\
\hline$M$ & 2.72 & 2.90 & 2.94 \\
\hline$S D$ & 0.47 & 0.45 & 0.42 \\
\hline \multicolumn{4}{|c|}{ Perceived effectiveness } \\
\hline$M$ & 2.83 & 2.92 & 3.04 \\
\hline$S D$ & 0.60 & 0.54 & 0.44 \\
\hline \multicolumn{4}{|c|}{ Perceived difficulty } \\
\hline$M$ & 2.06 & 2.15 & 2.36 \\
\hline \multirow[t]{2}{*}{$S D$} & 0.68 & 0.81 & 0.83 \\
\hline & \multicolumn{2}{|c|}{$\begin{array}{c}\text { African American } \\
n=320\end{array}$} & $\begin{array}{c}\text { White } \\
n=326\end{array}$ \\
\hline \multicolumn{4}{|c|}{ Personal and community control } \\
\hline$M$ & \multicolumn{2}{|c|}{2.83} & 2.88 \\
\hline$S D$ & \multicolumn{2}{|c|}{0.49} & 0.42 \\
\hline \multicolumn{4}{|c|}{ Perceived effectiveness } \\
\hline$M$ & \multicolumn{2}{|c|}{2.97} & 2.89 \\
\hline$S D$ & \multicolumn{2}{|c|}{0.57} & 0.50 \\
\hline \multicolumn{4}{|c|}{ Perceived difficulty } \\
\hline$M$ & \multicolumn{2}{|c|}{2.12} & 2.25 \\
\hline$S D$ & \multicolumn{2}{|c|}{0.80} & 0.76 \\
\hline
\end{tabular}

\section{Discriminant Function Analysis}

A discriminant function analysis examining how the three measures of perceived control combine to distinguish groups included 771 respondents. The results revealed only one significant discriminant function, although two were possible because the number of groups (K) in the analysis was three $(\mathrm{K}-1=2)$. The function explains $8.4 \%$ of the variance in the model (canonical correlation $=.29$ ). The variable function correlations were .58 for personal and community control, .69 for perceived effectiveness, 
and .52 for perceived difficulty. The discriminant function solution correctly classified $44 \%$ of the cases. Most of the errors occurred in assignments to Group 2 (74\% incorrectly classified) and the incorrect assignments were made equally in Groups 1 and 3 (45\% incorrectly classified). The function separates the nonparticipant group (Group 1) from the two participant groups. The discriminant function group centroids were $-.38, .00$, and .40 for the nonparticipant group, the low-level participant group, and the highlevel participant group, respectively.

\section{DISCUSSION}

The results of this study are consistent with empowerment theory (Berger \& Neuhaus, 1977; Schulz \& Israel, 1990; Rappaport, 1987; Zimmerman, in press; Zimmerman \& Rappaport, 1988). The combined variance of three measures of perceived control formed a single discriminant function dimension that distinguished groups defined by different amounts of participation. Individuals involved in community activities and organizations reported higher levels of this underlying dimension than nonparticipants. The underlying dimension formed by the discriminant function results may be interpreted as the intrapersonal component of psychological empowerment for members of voluntary organizations because it corresponds with the theoretical model of psychological empowerment proposed (i.e., correlates with the behavioral component) and replicates previous research. It is also noteworthy that the final results were not confounded by age, income, or education, because these variables were statistically controlled in analyses of group comparisons.

The results are similar to those reported by Zimmerman and Rappaport (1988) which found that 11 measures of perceived control combined to form a single discriminant function that distinguished groups defined by three different measures of participation. The combined variance of three measures of perceived control in this study also formed a single underlying construct that distinguished groups. The relatively high loadings of the perceived control measures on the discriminant function suggests that each variable contributed roughly equal amounts of variance to the underlying dimension that distinguished groups. These results provide additional support for the idea that the intrapersonal aspect of $\mathrm{PE}$ is conceptually different from univariate measures of perceived control (e.g., self-efficacy, locus of control) and that multivariate approaches may be necessary to adequately characterize the intrapersonal aspects of $\mathrm{PE}$ (Zimmerman, in press; Zimmerman \& Rappaport, 1988). 
The results extend psychological empowerment theory in two critical directions. First, the study examines psychological empowerment in a more diverse and randomly selected adult population than used in previous research. For example, Zimmerman and Rappaport (1988) included a sample of undergraduates to test their hypotheses, and although they did replicate their results on a community sample, it was not a stratified random sample like the one used in the present study. The sample studied by Kieffer (1984) included a small number of individuals selected for in-depth analyses. This research enhances the generalizability of the findings from these two studies by providing convergent evidence from a more representative sample.

The second contribution of this study was the inclusion of comparisons across race groups. The interaction effects between participation and race groups for the perceived control measures was stronger for African Americans than whites. Among nonparticipants, whites reported higher levels of the intrapersonal component of psychological empowerment than African Americans, but among participants, African American respondents reported higher levels of the intrapersonal component. This result can be interpreted in two different ways: (a) African Americans who have higher levels of perceived control are more likely than similar whites to participate in community groups and activities; or (b) participation in community groups and activities increases one's sense of control, and that this effect is greater for African American than for white participants. Participation in groups may result in enhanced sense of control for African Americans who have historically had less power than whites in the United States. Conversely, among those who were not community organization members or activists, whites reported greater perceived control than African Americans which reflects the racial inequalities in the distribution of power and resources in American society.

This study, however, does not address the question of whether participation enhances feelings of empowerment or whether individuals who chose to participate may already feel more empowered than those who do not participate. Several researchers have reported increases in activism and involvement, greater perceived competence and control, and decreases in alienation for nursing home residents (Langer \& Rodin, 1976), members of neighborhood associations (Ahlbrandt, 1984; Carr, Dixon, \& Ogles, 1976), individuals organizing over an environmental issue (Stone \& Levine, 1985), and union members (Denney, 1979). Kieffer (1984) also found that grass-roots leaders report greater feelings of control and competence as a result of their activism.

This study also extends research on PE by developing participation groups using a cluster analytic approach. Previous research used theoretically 
meaningful but somewhat subjective cutoffs for defining participation groups (Zimmerman \& Rappaport, 1988). For example, Zimmerman and Rappaport (1988) defined participation in two ways. First, level of participation was based on a composite score of the respondents' length of time involved with an organization, number of hours volunteered each month, attendance rate, and number of leadership positions. The sample was then split roughly by 1 standard deviation above and below the mean of the composite variable, and nonparticipants were assigned to their own group. A second participation measure was developed from the distribution of a measure that assessed number of community activities (e.g., writing a letter to public officials, demonstrating). This study used an analytic strategy to uncover natural separations of groups (i.e., cluster analysis) and combined both level of participation in community organizations and extent of involvement in community activities to define participation groups. Though the variables used in the cluster analysis were somewhat correlated, the community activities measure had the lowest correlations among the participation variables and primarily accounted for the difference between the two participation groups.

\section{Limitations}

This research has several limitations. First, we have extended empowerment theory only at the individual level of analysis (i.e., psychological empowerment). Although the measures used in the study assess respondents' perceived control in a community context, we did not examine organizational or community variables that may be related to empowerment. Efforts to further develop empowerment theory must begin to study empowerment at multiple levels of analysis in order to connect psychological empowerment with the larger social and political environment. This research could focus on characteristics of contexts that may enhance or inhibit empowering processes, or address factors associated with empowered organizations or communities. The work by Wandersman and his colleagues illustrates some strategies to examine how contextual factors may be associated with participation in neighborhood associations (Chavis \& Wandersman, 1990; Perkins, Florin, Rich, Wandersman, \& Chavis, 1990; Prestby et al., 1990). Future research on empowerment needs to integrate individual, organizational, and community levels of analysis.

Second, we examined only the intrapersonal and behavioral components of psychological empowerment, but the nomological network of psychological empowerment may also include an interactional component. The interactional component includes resource mobilization, a critical 
awareness of one's community, and problem-solving skills. These variables were not measured in the interview protocol so they could not be included in this study. Future research needs to include an assessment of the interactional component to further develop the construct of psychological empowerment. Another limitation of this research is the reliance on self-report data. Although previous research found no response bias effects in similar analyses (Zimmerman \& Rappaport, 1988), they were not tested in this study. Nevertheless, the use of interviews to collect data may have reduced some response biases (e.g., acquiescence) possible in pencil-andpaper surveys because the interviewer could detect it.

Another shortcoming of the results is that the discriminant function correctly classified less than half of the cases and explained less than $10 \%$ of the variance in the model. This may be due to the fact that the three measures of perceived control used in the study do not entirely represent the intrapersonal aspects of psychological empowerment. Measures of motivation to control and more specific measures of sociopolitical control (see Zimmerman \& Zahniser, 1991) were not represented, but may be essential aspects of the intrapersonal component of psychological empowerment. Other measurement issues may have also limited the results. For example, leadership and amount of organizational activity were measured only for the respondents' most important organization. Future studies may be improved if they include these participation measures for all of the respondents' organizational memberships because they may be more sensitive to individual differences in level of involvement.

The perceived difficulty measure may also be somewhat limited. First, it addressed only general community, school, and crime issues. Perceived difficulty may be represented more completely if it included a larger array of community problems such as racism, sexism, homelessness, and poverty. Crime and school issues were included in this measure because they were identified, during pretesting of the interview protocol, to be primary concerns of community members. The measure may also be somewhat limited because it asked respondents to indicate how difficult they thought it would be for informed people, not necessarily themselves, to influence different community problems. The intrapersonal component of PE is, however, hypothesized to include perceived control that is not necessarily personal in nature. Zimmerman and Rappaport (1988) found that PE was related to the belief that people in general, but not necessarily oneself, can influence social and political systems (i.e., control ideology). Nevertheless, future research may be improved if perceived difficulty also referred to the respondents' self-assessment of difficulty.

The fact that the analyses had different sample sizes is somewhat problematic, but the magnitude of the sample size even when respondents 
with missing data are omitted remained large. The largest reduction in the sample was for the MANOVA analyses which reduced the sample by less than one third. Mean substitution or some other data manipulation was not done because only age differed between respondents omitted from analyses and those included, and age was statistically controlled in covariate analyses. The data were not analyzed using only respondents with complete data, however, because we also wanted to maximize statistical power when possible. Statistical power (i.e., the probability of failing to reject the null hypothesis when it is false) was not addressed in earlier research (Kieffer, 1984; Zimmerman \& Rappaport, 1988), so it was especially useful to pay attention to this issue in order to enhance the programmatic nature of the present study. Ample statistical power remained for analyses with the reduced sample sizes.

Finally, it is important not to equate race and social class in the interpretation of these results. Though we did enter education and income as covariates in our analysis of race and participation group differences, such an analysis may oversimplify the social structural determinants (e.g., racism) that link race and social class. Future research that specifically examines how race and social class interact is necessary to fully understand how social structural factors may influence the development of psychological empowerment.

\section{CONCLUSION}

Researchers have found an association between participation in community organizations or activities and perceived control (Cole, 1981; Florin \& Wandersman, 1984; Stone \& Levine, 1985), but these studies have not directly tested psychological empowerment theory. The limited specification of PE theory is -not due to the myth that empowerment is more abstract and less operational than other psychological theories, rather it is due to the lack of attention given to developing the theory in the empirical literature. Empirical studies that test the theoretical connections among the three components of psychological empowerment - intrapersonal, behavioral, and interactional - are needed to advance our knowledge of the construct. Future research on PE also needs to examine sex differences and to continue exploring race and ethnic differences.

The development of psychological empowerment theory may also help improve the design and evaluation of community interventions. The theory suggests that interventions that provide genuine opportunities for individuals to participate may help them develop a sense of PE. Such interventions may be most effective if they include strategies for helping 
individuals develop the skills necessary to participate in decision making and problem solving. Although PE refers to the individual level of analysis, it should not be interpreted to mean that individuals are solely responsible for its development. Swift and Levin (1988) pointed out that an empowerment approach to prevention needs to consider environmental factors that may facilitate or hinder the development of PE. Consequently, empowering interventions might begin with an environmental assessment of the opportunities to participate and develop strategies to include participants in the design, implementation, and evaluation of an intervention. The focus of both empowerment theory and practice is to understand and strengthen processes and context where individuals gain mastery over decisions that affect their lives.

The results of this study raise several questions to be addressed in future research. How does psychological empowerment differ for members of different types of organizations (e.g., service, religious, political, social change organizations)? How does the amount of influence one holds in an organization affect the development of PE? What are aspects of the interactional component of psychological empowerment for members of community organizations? Efforts to address these questions may require an analysis of the context within which empowerment is studied. An ecological analyses may be useful for identifying contextual factors that enhance and inhibit the development of psychological empowerment. Such analysis could include an examination of the resources needed to achieve goals, a description of the relationships among leaders and members, and an investigation of past activities (see Kelly, 1986, for a more detailed explanation). The information gathered using an ecological framework may help identify those aspects of the interactional component of psychological empowerment that are contextually appropriate and culturally relevant, and should also help stimulate research on empowerment at multiple levels of analysis.

\section{REFERENCES}

Ahlbrandt, R. S., Jr. (1984). Neighborhoods, people, and community. New York: Plenum Press. Aldenderfer, M. S., \& Blashfield, R. K (1984). Cluster analysis. Beverly Hills: Sage.

Averred, B. (1974). Cluster analysis. London: Heinemann.

Berger, P. J., \& Neuhaus, R. J. (1977). To empower people: The role of mediating structures in public policy. Washington, DC: American Enterprise Institute for Public Policy Research.

Bray, J. H., \& Maxwell, S. E. (1982). Analyzing and interpreting significant MANOVAS. Review of Educational Research, 52, 340-367.

Carr, T. H., Dixon, M. C., \& Ogles, R. M. (1976). Perceptions of community life which distinguish between participants and nonparticipants in a neighborhood self-help organization. American Journal of Community Psychology, 4, 357-366. 
Chavis, D. M., \& Wandersman, A. (1990). Sense of community in the urban environment: A catalyst for participation and community development. American Journal of Community Psychology, 18, 55-81.

Cole, R. L. (1981). Participation in community service organizations. Journal of Community Action, 1, 53-60.

Cornell Empowerment Group (1989). Empowerment and family support. Networking Bulletin, 1, 1-23.

Denney, W. M. (1979). Participant citizenship in a marginal group: Union membership of California farm workers. American Joumal of Political Science, 23, 330-337.

Florin, P., \& Wandersman, A. (1984). Cognitive social learning and participation in community development. American Journal of Community Psychology, 12, 689-708.

Freire, P. (1973). Education for critical consciousness. New York: Seabury.

Gershick, T. J., Israel, B. I., \& Checkoway, B. (1990). Means of empowerment in individuals, organizations, and communities: Report on a retrieval conference. Ann Arbor: University of Michigan, Center for Research on Social Organization, Program on Conflict Management Alternatives.

Kelly, J. G. (1986). The ecology of prevention: Illustrating mental health consultation. Prevention in Human Services, 4, 1-36.

Kieffer, C. H. (1984). Citizen empowerment: A developmental perspective. Prevention in Human Services, 3, 9-36.

Kish, L. (1965). Survey Sampling. New York: Wiley.

Langer, E. J., \& Rodin, J. (1976). The effects of choice and enhanced personal responsibility for the aged: A field experiment in an institutional setting. Journal of Personality and Social Psychology, 34, 191-198.

McCarthy, J. D., \& Zald, M. N. (1977). Resource mobilization and social movements: A partial theory. American Journal of Sociology, 82, 1212-1241.

Paulhus, D. (1983). Sphere-specific measures of perceived control. Journal of Personality and Social Psychology, 44, 1253-1265.

Perkins, D. D., Florin, P., Rich, R. C., Wandersman, A., \& Chavis, D. M. (1990). Participation and the social and physical environment of residential block: Crime and community context. American Journal of Community Psychology, 18, 55-82.

Prestby, J. E., Wandersman, A., Florin, P., Rich, R., \& Chavis, D. (1990). Benefits, costs, incentive management, and participation in voluntary organizations: A means to understanding and promoting empowerment. American Journal of Community Psychology, $18,117-149$.

Rappaport, J. (1981). In praise of paradox: A social policy of empowerment over prevention. American Joumal of Community Psychology, 9, 1-25.

Rappaport, J. (1984). Studies in empowerment: Introduction to the issue. Prevention in Human Services, 3, 1-7.

Rappaport, J. (1985). The power of empowerment language. Social Policy, 16, 15-21.

Rappaport, J. (1987). Terms of empowerment/exemplars of prevention: Toward a theory for community psychology. American Journal of Community Psychology, 15, 121-148.

Sue, S., \& Zane, N. (1980). Learned helplessness theory and community psychology. In M. S. Gibbs, J. R. Lachenmeyer, \& J. Sigal (Eds.), Community psychology: Theoretical and empirical approaches (pp. 121-143). New York: Gardner.

Schulz, A. J., \& Israel, B. I. (1990). Empowerment and empowering processes: $A$ theory development seminar series, academic year 1988-1989. Unpublished manuscript, University of Michigan, Center for Research on Social Organization, Program on Conflict Management Alternatives, Ann Arbor.

Stone, R. A., \& Levine, A. G. (1985). Reactions to collective stress: Correlates of active citizen participation. Prevention in Human Services, 4, 153-177.

Swift, C., \& Levin, G. (1987). Empowerment: An emerging mental health technology. Journal of Primary Prevention, 8, 71-94.

Tatsuoka, M. M. (1971). Multivariate analysis: Techniques for educational and psychological research. New York: Wiley. 
Zimmerman, M. A. (1990a). Taking aim on empowerment research: On the distinction between psychological and individual conceptions. American Journal of Community Psychology, 18, 169-177.

Zimmerman, M. A. (1990b). Toward a theory of learned hopefulness: A structural model analysis of participation and empowerment. Journal of Research in Personality, 24, 71-86.

Zimmerman, M. A. (in press). Empowerment theory: Psychological, organizational and community levels of analysis. In J. Rappaport \& E. Seidman (Eds.), The handbook of community psychology, New York: Plenum Press.

Zimmerman, M. A., \& Rappaport, J. (1988). Citizen participation, perceived control, and psychological empowerment. American Journal of Community Psychology, 16, 725-750.

Zimmerman, M. A., \& Zahniser, J. H. (1991). Refinements of sphere-specific measures of perceived control: Development of a socio-political control scale. Journal of Community Psychology, 19, 189-204. 